\title{
BMJ Open Patient views of therapeutic interchange of ACE inhibitors in Australian primary care: a qualitative study
}

Tessa Marshall (D), Hok Lim, Phyllis Lau

To cite: Marshall T, Lim H, Lau P. Patient views of therapeutic interchange of ACE inhibitors in Australian primary care: a qualitative study. BMJ Open 2021;11:e044806. doi:10.1136/ bmjopen-2020-044806

- Prepublication history and additional supplemental material for this paper are available online. To view these files, please visit the journal online (http://dx.doi.org/10.1136/ bmjopen-2020-044806)

Received 14 September 2020 Accepted 24 June 2021

\section{A) Check for updates}

(c) Author(s) (or their employer(s)) 2021. Re-use permitted under CC BY-NC. No commercial re-use. See rights and permissions. Published by BMJ.

Department of General Practice, The University of Melbourne, Melbourne, Victoria, Australia

Correspondence to

Dr Phyllis Lau;

plau@unimelb.edu.au

\section{ABSTRACT}

Objectives In Australia, therapeutic interchange of angiotensin-converting enzyme (ACE) inhibitors could generate savings for patients and the Pharmaceutical Benefits Scheme (PBS). The PBS subsidises nine drugs in the ACE inhibitor class. These drugs are therapeutically equivalent, but the price varies between each drug. Patients are key players in successful therapeutic interchange programmes, but little is known about their views. This study aims to explore patient views of therapeutic interchange of ACE inhibitors in Australian primary care.

Design Qualitative exploratory research study using semi-structured interviews, asking participants about therapeutic interchange and their attitude towards hypothetically switching ACE inhibitors. Data were analysed thematically.

Setting Australian primary care.

Participants Fourteen adults in Australia currently taking an ACE inhibitor, recruited via general practices and pharmacies, social media and professional networks. Findings Five key themes were identified: participants' limited understanding of medication; the expectation that a new drug would be 'the same'; the view that choice, convenience and fear of change outweigh the cost; altruism; and trust in health professionals, particularly participants' own general practitioner (GP).

Conclusions Patients' limited understanding of medication changes poses a barrier to therapeutic interchange. Clinicians should explore patients' understanding and expectations of therapeutic interchange. Counselling from trusted health professionals, particularly GPs, could ameliorate concerns. Policymakers implementing therapeutic interchange programmes should ensure a trusted GP directs medication changes.

\section{INTRODUCTION}

Angiotensin-converting enzyme (ACE) inhibitors are a class of drugs commonly prescribed for hypertension, heart failure, chronic kidney disease and after myocardial infarction. ${ }^{1}$ These drugs are a significant expense for patients and the Pharmaceutical Benefits Scheme (PBS): in the 2018/2019 financial year, patients spent \$A92 million on ACE inhibitors and the PBS contributed \$A63 million, excluding for combination products (as per a December 2019 email

\section{Strengths and limitations of this study}

This is the first study that explores patients' views on therapeutic interchange of ACE inhibitors in Australian primary care.

- This study includes participants from a range of demographics, including retirees, full-time carers and educated professionals in three Australian states.

- The study was limited by the absence of participants under 40 , residing in rural areas or who earn a low income but are above the threshold for medication concessions.

from PBS information). Each of the nine ACE inhibitors on the PBS is considered therapeutically equivalent with no significant clinical differences, so no specific ACE inhibitor is recommended in common blood pressure reduction guidelines. ${ }^{12}$ A clinician's choice of ACE inhibitor may be influenced by dosing regimens and minor differences in side effect profiles. ${ }^{3}$ However, without definitive evidence on which drug should be first-line, cost and practical considerations become important.

Therapeutic interchange is where an alternative drug, which may be chemically different and have different pharmacokinetic properties, is used on the premise that this alternative has similar efficacy, outcomes and safety as the original. This is less commonly implemented than generic substitution, which replaces the original drug with a product containing identical amounts of the same active ingredient and is the same in dosage, safety, strength and use. ${ }^{5}$ Generic substitution is an established cost-saving measure in Australia, whereas therapeutic interchange is less widespread. ${ }^{6}$

Therapeutic interchange occurs around the world in hospitals, general practices and community pharmacies. ${ }^{7-10}$ Research suggests it can reduce healthcare system costs by using therapeutically equivalent but lowercost drugs. ${ }^{11-13}$ In Australia, a hospital-based 
therapeutic equivalence programme had the dual benefit of saving the health service $\$ A 1$ million per year and increasing junior doctors' familiarity with the preferred drugs, potentially reducing prescribing errors. ${ }^{14}$ Therapeutic interchange of ACE inhibitors could save money for patients who are not concessional benefit card holders. Depending on the type and brand, ACE inhibitors cost between $\$ \mathrm{~A} 12.50$ and $\$ \mathrm{~A} 20.47$ for a month's supply, of which these patients pay the full price. ${ }^{1516}$ For concessional benefit card holders, the PBS subsidises these medications so that patients only pay $\$ A 6.60$ for a month's supply. ${ }^{15} 16$ Therefore, using a cheaper ACE inhibitor would lead to savings for the PBS. New Zealand's model demonstrates the cost-effectiveness of therapeutic interchange: unlike Australia, New Zealand restricts the number of drugs subsidised in each class, for example, only subsidising six ACE inhibitors. ${ }^{17}$ All of these (except for combinations and a liquid formulation) are purchased by New Zealand's Pharmaceutical Management Agency (PHARMAC) at a cheaper price than any ACE inhibitor in Australia: the most expensive is perindopril, which costs PHARMAC just NZ $\$ 6.30$ for a month's supply. ${ }^{17}$ New Zealand's model demonstrates that Australia could further restrict the number of ACE inhibitors available. This would lead to savings for both general patients who pay the full price for their ACE inhibitor, and for the PBS when subsidising the cost of ACE inhibitors for concession holders.

Patients are key players in successful therapeutic interchange programmes, but there is limited research into patients' views, particularly of ACE inhibitors despite their large savings potential. ${ }^{18}$ Patients' understanding of therapeutic interchange is generally poor, and while patients desire face-to-face discussion with doctors or pharmacists before changing medications, this does not always occur despite its potential to improve patient understanding. ${ }^{19-21}$ However, most research indicates that patients are generally open to trialling therapeutic interchange and mostly satisfied afterwards. ${ }^{2022} 23$

There is a paucity of research on patient experiences of therapeutic interchange in Australia and most studies elsewhere examine proton pump inhibitors (PPIs) or statins rather than ACE inhibitors. ${ }^{19-26}$ Due to healthcare system differences between countries, research on therapeutic interchange in an Australian context is necessary, particularly for drugs with large savings potential such as ACE inhibitors. Additionally, blood pressure medications require further investigation because patients may perceive them differently from PPIs or 3-hydroxy-3-meth ylglutaryl-coenzyme A (HMG-CoA) reductase inhibitors.

This research aims to explore patients' views on therapeutic interchange of ACE inhibitors in primary care. Using semi-structured interviews, people currently on an ACE inhibitor were asked about their views on therapeutic interchange, including their knowledge, willingness to trial therapeutic interchange and their views on restricting the number of ACE inhibitors on the PBS. Findings may guide policymakers in rationalising ACE inhibitor prescribing, and help general practitioners (GPs) reduce costs for patients and the PBS.

\section{METHODS \\ Study design}

This is a qualitative exploratory research study using a phenomenological approach. ${ }^{27}$ Adults (over 18 years old) currently taking an ACE inhibitor were recruited purposively to participate in semi-structured interviews about their views on hypothetically switching ACE inhibitors and on aspects of therapeutic interchange.

\section{Recruitment}

Participants were recruited through GPs and pharmacists via researchers' professional networks. GPs and pharmacists offered the project plain language statement to patients on ACE inhibitors and, if consent was provided, passed on participant contact details. Posters were also put in general practice waiting rooms and pharmacies. Additionally, participants were recruited through social media and noticeboards at the University of Melbourne and the Stroke Foundation (see online supplemental file $1)$.

When someone reached out after seeing these materials, eligibility was confirmed by confirming the patient's details and medication, and a plain language statement provided. The interviewer gained verbal consent before proceeding with the interview.

We planned to recruit 10-12 participants but continued recruiting and interviewing participants until we reached data saturation. We used a maximum variation sampling matrix to identify adults on ACE inhibitors of varied ages, occupations and from multiple Australian states, to elicit a diverse range of opinions. People were excluded if they did not speak English or had cognitive impairments that could lead to difficulties with interviews. Excluded participants were notified of their ineligibility at the time of contact.

\section{Data collection}

Each participant took part in one audio-recorded individual semi-structured interview, either face-to-face or via phone or videoconferencing after social distancing measures were implemented in Australia during the COVID-19 pandemic. TM, a female medical student, interviewed all participants and recorded field notes afterwards. Findings from a literature review guided the development of the interview questions (table 1), which were piloted with three laypeople and with the three researchers.

\section{Data processing and analysis}

Analysis was conducted inductively using a phenomenological lens to explore participants' lived experience and then deductively guided by the two categories of barriers and facilitators to therapeutic interchange. 
Table 1 Interview guide

\begin{tabular}{ll}
\hline Topic & Question(s) \\
\hline Demographics & Could you tell me your age and what you do day-to-day? \\
Use of ACEls & $\begin{array}{l}\text { Could you tell me about the blood pressure medication you } \\
\text { are taking? }\end{array}$
\end{tabular}

\section{Probes/prompts}

If you switched, who switched the medication?

(GP/hospital/specialist)

What BP medication are you taking?

Have you ever switched this medication?

How long have you been on an ACEI?

Do you know who first prescribed an ACEl for you?

\begin{tabular}{|c|c|c|}
\hline $\begin{array}{l}\text { Understanding of } \\
\text { ACEls }\end{array}$ & $\begin{array}{l}\text { To your knowledge, what is the reason that the } \\
\text { GP prescribed an ACEI for you? } \\
\text { Before this study, were you aware that there are different } \\
\text { types of ACEls? }\end{array}$ & $\begin{array}{l}\text { To your knowledge, what are the differences } \\
\text { between the different types of ACEls? } \\
\text { Where did you get this knowledge from? }\end{array}$ \\
\hline Cost & $\begin{array}{l}\text { How important to you is the cost of your regular blood } \\
\text { pressure medication? }\end{array}$ & $\begin{array}{l}\text { If it meant you could save money on } \\
\text { medications, what would you think about } \\
\text { switching ACEls? Why? } \\
\text { If it meant the cost to the taxpayer was } \\
\text { reduced, what would you think about } \\
\text { switching ACEls? Why? }\end{array}$ \\
\hline $\begin{array}{l}\text { Restricting the } \\
\text { number of ACEls } \\
\text { on the PBS }\end{array}$ & $\begin{array}{l}\text { Some countries restrict the number of ACEI that are funded, } \\
\text { for example, three compared to nine in Australia. } \\
\text { What do you think are the pros and cons of reducing the } \\
\text { number in Australia? }\end{array}$ & $\begin{array}{l}\text { What is your opinion on reducing the number } \\
\text { of ACEl funded to reduce the cost to the } \\
\text { PBS? }\end{array}$ \\
\hline $\begin{array}{l}\text { Opportunity to } \\
\text { raise other points }\end{array}$ & $\begin{array}{l}\text { Is there anything else you would like to say about how GPs } \\
\text { prescribe ACEls? }\end{array}$ & \\
\hline
\end{tabular}

ACEI, ACE inhibitor; BP, blood pressure; GP, general practitioner; PBS, Pharmaceutical Benefits Scheme.

Researcher TM transcribed all interviews and imported the transcripts into the NVivo qualitative data analysis software to organise and inductively code the data. ${ }^{28}$ Four initial transcripts were also independently coded by researchers PL, a female academic pharmacist experienced in qualitative and primary care research, and HL, a male GP with a pharmacist background. Codes were then grouped under patterns identified and patterns were deductively condensed into major themes and categorised under barriers or facilitators to therapeutic interchange. Throughout the iterative process, differences in codes and themes were regularly discussed among the research team until consensus was reached. Data saturation was determined to be reached when no original codes arose from the data.
We used the Consolidated Criteria for Reporting Qualitative Research to write this article (see online supplemental file 2). ${ }^{29}$

\section{Consent and confidentiality}

Participants gave consent for researchers to contact them or initiated contact with researcher TM. TM explained the project in detail, read the consent statement and obtained verbal consent from each participant before starting the interview. Verbal rather than written consent was obtained to make the process easier for participants, as many interviews were conducted via telephone with participants with limited online literacy. Only researchers had access to audio data, which was deleted from 
Table 2 Demographics of participants

\begin{tabular}{|l|l|}
\hline Characteristic & $\begin{array}{c}\text { Number of } \\
\text { participants }\end{array}$ \\
\hline $\begin{array}{l}\text { Gender } \\
\text { Male }\end{array}$ & 7 \\
\hline Female & 7 \\
\hline Age (years) & \\
\hline $41-50$ & 2 \\
\hline $51-60$ & 2 \\
\hline $61-70$ & 6 \\
\hline $71-80$ & 4 \\
\hline State of residence & \\
\hline Victoria & 10 \\
\hline New South Wales & 3 \\
\hline Queensland & 1 \\
\hline Employment status & \\
\hline Employed & 4 \\
\hline Retired & 8 \\
\hline Full-time carer & 2 \\
\hline Concession status & \\
\hline Receiving medication concession & 10 \\
\hline Not receiving medication concession & 4 \\
\hline
\end{tabular}

recording devices immediately after being transferred to a password-protected file.

Transcripts were de-identified and stored separately from participant details in confidential files in passwordprotected computers. Identifying information such as names and locations was removed from quotes.

\section{Patient and public involvement statement}

Patients and the public were not involved in the design, conduct, reporting or dissemination of our research.

\section{FINDINGS}

Fourteen participants between the ages of 41 and 80 years (mean 64years old) were interviewed. Demographic information is shown in table 2. One interview occurred in person before social distancing, one via video conferencing and the rest by telephone. Fourteen interviews were completed, lasting between 12 and 47 minutes and audio-recorded using an iPhone or laptop. The average interview length was 26 minutes.

Five key themes were identified. Three were considered barriers to therapeutic interchange: (1) participants' limited understanding of medication, (2) the expectation that a new drug would be 'the same' and (3) the view that choice, convenience and fear of change outweigh the cost. Facilitators of therapeutic interchange included (4) participants' trust in health professionals, particularly their own GP, and (5) participants' altruism.

\section{Limited understanding of medications}

Except for one participant who was a GP, participants had little understanding that multiple blood pressure medications exist and had no understanding that their medication was an ACE inhibitor.

I don't know about different types of blood pressure medication. (P10)

I have heard of ACE inhibitors, but I'll be honest with you, I don't know much about them. (P3)

Some admitted that they had forgotten the details of their medication despite being informed.

It just goes in one ear and out the other with me. (P14)

Some participants wanted to be told more about their medications and have regular medication reviews. Participants thought the lack of ongoing counselling about their medication contributed to their poor understanding.

If they could just go over every so often about what medications you're taking, whether they're okay to take other medication with, and not have to remind them. (P10)

Most participants consulted the same sources to find medication information, including health professionals, the internet, friends and even medical literature.

If I've forgotten to ask the doctor, I'll go to Dr Google ... Sometimes I ask the chemist if I've got queries. You know, sometimes a friend will say they're on medication for blood pressure. Ah yeah, what are you taking? How many milligrams have you got? (P12)

I use my university library if I want to look up these sorts of things ... I generally just do a literature search. (P13)

One participant, a GP, presumed patients obtained information from the medication pamphlet. However, information leaflets were not mentioned by other participants.

Well, there's obviously just the drug information, product information that's actually just in the box. So, I know, I personally haven't read it because I feel I know about perindopril enough. I know my patients would look at that stuff. (P7)

The reported lack of knowledge, and specifically lack of counselling, contributed to some participant's hesitation regarding therapeutic interchange. Without this knowledge, they had no persuasive reason to agree to change medications, particularly if there was no direct cost reduction for the participant.

I don't have any ideas [why a GP would change medications], no. If that was working, I don't know why you would change it. (P9) 
We'll save the government a bit of money to do thisit's not a very persuasive argument, I think. Not that I'm against the idea, but personally I wouldn't find it very persuasive as a patient. $(\mathrm{P} 7)$

\section{Expectation that a new drug would be 'the same'}

When asked whether they would consider changing ACE inhibitors, most participants said they would seek reassurance that the new medication would be 'the same'. The meaning of this differed from participant to participant. Several were open to change provided the effect and side effects were the same.

As long as I didn't have any side effects and it's keeping my blood pressure low, it's fine by me. (P10)

Others approved of generic substitution but hesitated to change to a different drug within the same class.

If it's an identical generic brand, it wouldn't bother me taking it, but if it's a different drug then I would say no because it's not what I was prescribed. (P13)

A few participants were very cautious, refusing generic substitutions because of slight differences.

I never get a generic dosage made up because I prefer the brand ... It's just what I've read in the past. That there is a slight difference although it's not great between the quality and the efficacy of generics rather than the original and so I've chosen to have the original pharmacology. (P6)

\section{Choice, convenience and fear of change outweigh cost}

No participant said they couldn't afford the current cost of their medication. Nine participants were retirees or full-time carers receiving a concessional benefit, which limits the copayment for each medication to $\$ \mathrm{~A} 6.60{ }^{30}$ The other five participants pay the full copayment (up to $\$$ A20.47 depending on the ACE inhibitor). ${ }^{15}$

Some participants viewed price as immaterial:

If I had to pay a thousand dollars a month, I would pay a thousand dollars. Because I really don't want to go back to hospital to have another heart operation. (P14)

Others, particularly pensioners who purchased multiple medications, emphasised that a cost increase would be an issue.

I can afford it, so I probably don't worry about it. But as I said to you if I had to pay more for it, it'd be a different story. (P1)

If I had to pay for it along with other medication I'm on and other family members, it probably wouldn't have been possible to take it at all ... I would have had to choose the one that's most necessary. (P4)

Several factors were considered more important than reducing cost. Some participants valued convenience.
It's not the cost of it. The nuisance of having to go to the doctor and have a review, and then going, well, monthly. (P2)

Realistically for me the inconvenience of going to the pharmacy once a month is a much bigger deal than the cost. (P7)

The ease of remaining on the same medication, rather than risking change, was evident.

I'd probably suggest that I'd just stay with something that works ... if there's no problem why would you change? (P9)

Most participants were hesitant to change medications when it wasn't medically necessary. Participants cited fear of destabilising their health, particularly where multiple conditions were involved:

Because I'm on so many tablets, one of those tablets might disrupt the whole lot. (P1)

Some participants were concerned about the risk of new side effects if they changed medications.

I haven't got the side effects. So why change when everything's sort of working well? (P11)

Choice was also highly valued by some participants, particularly when discussing restricting the number of ACE inhibitors available on the PBS.

Different medications suit different people, so I suppose having a choice is a good thing, because if you've only got maybe three... what if those three don't agree with people? (P3)

I think our bodies do need choices ... and I think there are people around who do need different ones ... even if it's only one person. That one person is important. (P12)

One participant also considered where the medication was produced.

If it was an Australian company that was producing it, I might stick with that. (P2)

\section{Trust in health professionals, particularly own GP}

Most participants expressed deep trust in their health professionals, particularly long-term GPs with whom participants had built a relationship over years or even decades. These participants often unquestioningly accepted their GP's decisions.

I just depend on [GP]. I've been going in, I don't know, forty years, so he knows us back to front. (P14)

Some participants voiced similar long-term relationships with their pharmacist.

I would be asking the chemist as well, what the chemist knows. But again, yeah see the chemist has been my chemist for quite a few years as well. (P12) 
However, many participants were reluctant about pharmacists implementing therapeutic substitution. The main concern was the pharmacist's limited knowledge of their history.

Obviously they know what they're doing and I trust them implicitly but I wouldn't necessarily think they have the background to do the full analysis and prescription. (P13)

A pharmacist doesn't know my history, where my doctor knows everything about me from my head to my toes. So, I go by what the doctor said, always. (P14)

Some participants considered the impact of pharmacists' business interests on their role in therapeutic substitution but came to different conclusions about whether this would benefit or harm the patient.

But they're also individual businesspeople by and large. And there can always be conflicts of interest, I know as there can be with doctors. Doctors are a little bit further away from the direct business profit model that pharmacists are in, operating small businesses in a highly competitive context ... issues do come up about potential conflicts of interest that can be business-driven as well as clinically driven. And that's why I do not want pharmacists to make decisions for me in regard to prescriptions. (P6)

If you're buying [medications from pharmacists] and they're making them, well they're not going to cheat you otherwise you don't come back at all. (P8)

A handful of participants wanted to be more involved in decisions about their care.

The doctor used to tell you what they were putting you on and you accepted it. So, I would say it's not like today... I'm trying to come out of that to say, hopefully, I say well why are you changing me? What's going on? (P1)

\section{Altruism \\ Many participants supported therapeutic interchange if it improved the lives of others. Some were willing to change their ACE inhibitor to one that was cheaper for the PBS to subsidise. \\ I might shift, if it was probably cheaper for the tax- payer ... there's going to be people out there who haven't got the money. So, I might if [participant's GP] suggested it would be cheaper for other people I might try something else, yes. (P3)}

Others were open to restricting the number of ACE inhibitors on the PBS to reduce costs.

If the savings meant for some nominal difference to myself but if the overall savings was to benefit those poor folks that, there are only sort of say, a hundred of them in the country, that require a medication, then by all means. Because there's only so much money that can go round and that would be a good thing as far as that's concerned. (P2)

\section{DISCUSSION}

To our knowledge, this is the first study that explores patients' views on therapeutic interchange of ACE inhibitors in Australian primary care. The participants in our study had a limited understanding of therapeutic interchange, which is consistent with other literature and may be a barrier to therapeutic interchange. ${ }^{19-21}$ They were mostly unconcerned about the cost of medications. They favoured face-to-face discussions with their GPs in order to direct medication changes. While participants trusted their GP deeply, many were uncomfortable with therapeutic substitution by pharmacists.

The information about therapeutic interchange provided before the interview was kept deliberately brief to avoid biasing participants' views. However, information from clinicians may alter participants' opinions. In therapeutic interchange programmes where participants could discuss the change with their doctor, the majority of patients approached agreed to change medications. ${ }^{22} 23$ However, in a Slovenian survey where there was no opportunity to ask questions, only a quarter of respondents suggested they were open to therapeutic substitution. ${ }^{19}$ This could suggest that patients are more open to therapeutic interchange in non-hypothetical situations.

While the current study did not assess patients' attitudes after therapeutic interchange, research that does examine this has conflicting results. Studies that only survey those who successfully change medications report high patient satisfaction after therapeutic interchange. ${ }^{22-24}$ However, other studies that include unsuccessful interchange attempts demonstrated overall reduced satisfaction. ${ }^{20}{ }^{25}$ Future research could implement a therapeutic interchange programme in Australian primary care to evaluate participants' views both before and after changing medications.

Our participants' lack of concern about medication costs mirrors patient views across Europe, where many of the patients surveyed paid only a minimal copay fee. ${ }^{1922} 30$ On the other hand, in a set of online surveys across four US states, an overwhelming majority agreed that outof-pocket costs were important to their decisions about medications. ${ }^{31-34}$ Given that medication copayments in Australia more likely resemble those in Europe than the USA, it is unsurprising that Australian participants were similarly unconcerned about medication costs.

While the economic benefit of therapeutic interchange has been evaluated in Australian hospitals, our study is the first to examine a patient perspective of therapeutic interchange in Australian primary care. ${ }^{26}$ One researcher conducted all interviews for continuity, with support from experienced researchers. This study was also strengthened by including participants from a range of demographics, including retirees, full-time carers and educated professionals, residing in three Australian states. However, we were unable to recruit anyone under 
the age of 40, and all participants resided in metropolitan areas. Moreover, half the participants were old-age pensioners and were perhaps over-represented. There is little representation of people who earn a low income but are above the threshold for medication concessions. Another limitation is that some participants were already known to the interviewer or had mutual contacts, while others were recruited via their GPs. These pre-existing relationships may have led participants to overstate their enthusiasm.

Our study identifies a range of factors considered by patients when contemplating therapeutic interchange. We have identified a central role for trusted GPs in counselling patients about therapeutic interchange, which could improve knowledge and ameliorate patient concerns. Policymakers introducing therapeutic interchange in primary care should ensure GPs are central in this process. They should also consider other factors important to patients, including convenience, choice and the altruistic impact of therapeutic interchange. While this study presented participants with hypothetical situations, future research could instigate therapeutic interchange and investigate the subsequent patient experience. Additionally, thoroughly evaluating patients' understanding of therapeutic interchange and ACE inhibitors could help clinicians improve counselling.

\section{Twitter Tessa Marshall @tessarmarshall}

Contributors PL, HL and TM all contributed to the design of the study, the development of the study methodology, including the interview schedule and analysis plan, the recruitment of participants and the analysis of the transcribed interviews. TM conducted and transcribed all interviews. TM drafted the first draft of this manuscript; PL, HL and TM all read, provided critical revisions and approved the final manuscript.

Funding The authors have not declared a specific grant for this research from any funding agency in the public, commercial or not-for-profit sectors.

Competing interests None declared.

Patient consent for publication Not required.

Ethics approval This research project is approved by the Human Research Ethics Committees from The University of Melbourne (Ethics ID 1955072.2).

Provenance and peer review Not commissioned; externally peer reviewed.

Data availability statement No data are available. No raw data will be made available due to the re-identifiable nature of qualitative interview data.

Supplemental material This content has been supplied by the author(s). It has not been vetted by BMJ Publishing Group Limited (BMJ) and may not have been peer-reviewed. Any opinions or recommendations discussed are solely those of the author(s) and are not endorsed by BMJ. BMJ disclaims all liability and responsibility arising from any reliance placed on the content. Where the content includes any translated material, BMJ does not warrant the accuracy and reliability of the translations (including but not limited to local regulations, clinical guidelines, terminology, drug names and drug dosages), and is not responsible for any error and/or omissions arising from translation and adaptation or otherwise.

Open access This is an open access article distributed in accordance with the Creative Commons Attribution Non Commercial (CC BY-NC 4.0) license, which permits others to distribute, remix, adapt, build upon this work non-commercially, and license their derivative works on different terms, provided the original work is properly cited, appropriate credit is given, any changes made indicated, and the use is non-commercial. See: http://creativecommons.org/licenses/by-nc/4.0/.

\section{ORCID iD}

Tessa Marshall http://orcid.org/0000-0003-2634-1172
REFERENCES

1 ACE inhibitors. ACE inhibitors - Australian medicines handbook, 2019. Available: https://amhonline-amh-net-au.ezp.lib.unimelb.edu. au/chapters/cardiovascular-drugs/antihypertensives/ace-inhibitors

2 Blood Pressure Reduction | Therapeutic Guidelines. Angiotensin convert. enzyme Inhib. Reduce blood press, 2019. Available: https:// tgldcdp-tg-org-au.ezp.lib.unimelb.edu.au/viewTopic?topicfile=bloodpressure-reduction\&guidelineName=Cardiovascular\#toc_d1e249

3 Weber MA, Schiffrin EL, White WB, et al. Clinical practice guidelines for the management of hypertension in the community. $J$ Clin Hypertens 2014;16:14-26.

4 Sun W, Zhang H, Guo J, et al. Comparison of the efficacy and safety of different ACE inhibitors in patients with chronic heart failure. Medicine 2016;95:e2554.

5 FDA. Research C for DE and. Drugs@FDA Glossary of Terms, 2018. Available: https://www.fda.gov/drugs/drug-approvals-anddatabases/drugsfda-glossary-terms

6 Holmes David R, Granger Christopher B, Limacher Marian C. ACCF/ AHA 2011 health policy statement on therapeutic interchange and substitution. Circulation 2011;124:1290-310.

7 Adrover-Rigo M, Fraga-Fuentes M-D, Puigventos-Latorre $\mathrm{F}$, et al. Systematic literature review of the methodology for developing pharmacotherapeutic interchange guidelines and their implementation in hospitals and ambulatory care settings. Eur J Clin Pharmacol 2019;75:157-70.

8 Vanderholm T, Klepser D, Adams AJ. State approaches to therapeutic interchange in community pharmacy settings: legislative and regulatory authority. JMCP 2018;24:1260-3.

9 Canadian Pharmacists Association. Pharmacists' scope of practice in Canada, 2020. Available: https://www.pharmacists.ca/cpha-ca/ assets/File/cpha-on-the-issues/Scope\%20of\%20Practice\%20in\% 20Canada_Jan2020.pdf

10 HSE.ie. Preferred drugs, 2020. Available: https://www.hse.ie/eng/ about/who/cspd/ncps/medicines-management/preferred-drugs/ preferred-drugs.html

11 Willey VJ, Reinhold JA, Willey KH. Clinical and economic outcomes in patients switched to simvastatin in a community-based family medicine practice: clinical and economic outcomes in patients switched to simvastatin. Int J Clin Pract 2010;64:1235-8.

12 Schneeweiss S, Maclure M, Dormuth C, et al. A therapeutic substitution policy for proton pump inhibitors: clinical and economic consequences. Clinical Pharmacology \& Therapeutics 2006;79:379-88.

13 Moon JC, Bogle RG. Switching statins. BMJ 2006;332:1344-5.

14 Chynoweth T, Larmour I. Therapeutic equivalence program: continued economic benefits in the context of rising costs and increased demand. Aust Health Rev Publ Aust Hosp Assoc 2018;43:585-90.

15 Australian Government Department of Health. Schedule of pharmaceutical benefits (Volume 1 - general schedule), 2020. Available: https://www.pbs.gov.au/publication/schedule/2020/02/ 2020-02-01-general-schedule-volume-1.pdf

16 Medicare Australia. Medicare Australia - statistics - pharmaceutical benefits schedule item statistics, 2020. Available: http:// medicarestatistics.humanservices.gov.au/statistics/pbs_item.jsp

17 Schedule Online. Pharmaceutical benefits schedule item reports, 2019. Available: https://www.pharmac.govt.nz/wwwtrs/ ScheduleOnline.php?code=A070701

18 Brinton EA. Understanding patient adherence and concerns with statins and medication discussions with physicians (action): a survey on the patient perspective of dialogue with healthcare providers regarding statin therapy. Clin Cardiol 2018;41:710-20.

19 Marđetko N, Kos M. Patients' knowledge and attitude towards therapeutic reference pricing system in Slovenia. Int J Clin Pharm 2016;38:1301-10.

20 Krska J, Allison K, Delargy M, et al. Implementing a statin switching programme in primary care: patients' views and experiences. $\mathrm{Br} J$ Clin Pharmacol 2012;74:147-53.

21 Sodorff MM, Galt KA, Galt MA, et al. Patient perceptions of a proton pump inhibitor therapeutic interchange program across the continuum of care. Pharmacotherapy 2002;22:500-12.

22 O'Connor G, O'Keeffe D, Darker C, et al. Patient acceptability and experiences of therapeutic switching of proton pump inhibitors within the National preferred drugs initiative in Ireland. Ir J Med Sci 2017;186:631-9.

23 Usher-Smith JA, Ramsbottom T, Pearmain H, et al. Evaluation of the cost savings and clinical outcomes of switching patients from atorvastatin to simvastatin and losartan to candesartan in a primary care setting. Int J Clin Pract 2007;61:15-23.

24 Condra LJ, Morreale AP, Stolley SN. Assessment of patient satisfaction with a formulary switch from omeprazole to lansoprazole 
in gastroesophageal reflux disease maintenance therapy. $A m \mathrm{~J}$ Manag Care 1999;5:631-8.

25 Nelson WW, Vermeulen LC, Geurkink EA, et al. Clinical and humanistic outcomes in patients with gastroesophageal reflux disease converted from omeprazole to lansoprazole. Arch Intern Med 2000;160:2491-6.

26 Larmour I, Pignataro S, Barned KL, et al. A therapeutic equivalence program: evidence-based promotion of more efficient use of medicines. Medical Journal of Australia 2011;194:631-4.

27 Moustakas C. Phenomenological research methods. Thousand Oaks: SAGE Publications Ltd, 1994.

28 QSR International Pty Ltd. NVivo qualitative data analysis software, version 12. Doncaster Victoria, Australia: QSR International Pty Ltd, 2018.

29 Tong A, Sainsbury P, Craig J. Consolidated criteria for reporting qualitative research (COREQ): a 32-item checklist for interviews and focus groups. International Journal for Quality in Health Care 2007;19:349-57.
30 Health AGD of Pharmaceutical Benefits Scheme (PBS). About the PBS, 2020. Available: http://www.pbs.gov.au/info/about-the-pbs

31 Global Healthy Living Foundation. Tennessee patient Sentiment toward non-medical drug switching, 2016. Available: https:// creakyjoints.org/advocacy/tennessee-patient-sentiment-toward-nonmedical-drug-switching/

32 Global Healthy Living Foundation. Florida patient Sentiment toward non-medical drug switching - CreakyJoints, 2016. Available: https:// creakyjoints.org/advocacy/florida-patient-sentiment-toward-nonmedical-drug-switching/

33 Global Healthy Living Foundation. Massachusetts patient Sentiment toward non-medical drug switching, 2017. Available: https:// creakyjoints.org/advocacy/massachusetts-patient-sentiment-towardnon-medical-drug-switching/

34 Global Healthy Living Foundation. New York patient Sentiment toward non-medical drug switching, 2018. Available: https:// creakyjoints.org/advocacy/new-york-patient-sentiment-toward-nonmedical-drug-switching/ 